\title{
Pembangunan $e$-Business Berbasis Website Berdasarkan Kerangka PIECES (Studi Kasus: Aspin Photography \& Video Pro)
}

\author{
Fransiskus Tjiptabudi \\ Sistem informasi STIKOM Uyelindo Kupang \\ tjiptabudifrans@gmail.com
}

\begin{abstract}
ABSTRAK
Aspin Photography \& Video Pro adalah sebuah perusahaan di Kupang-NTT yang proses bisnis utamanya bergerak pada bidang jasa fotografi dan video shooting. Saat ini Aspin Photography \& Video Pro mengalami kemajuan bisnis yang cukup pesat dan telah memiliki banyak pelanggan sejalan dengan semakin boomingnya fotografi saat ini. Seiring dengan perkembangan perusahaan ini, proses bisnis yang dilakukan mulai dari promosi hingga transaksi menimbulkan masalah, karena segala sesuatunya masih dilakukan secara konvensional. Tujuan dari penelitian ini adalah untuk merancang dan membangun sebuah $e$-Business berbasis website yang bertujuan untuk mempermudah proses promosi dan transaksi bisnis pada Aspin Photography \& Video Pro secara daring. Website eBusiness ini dibangun berdasarkan hasil analisis permasalahan dengan berpedoman pada kerangka PIECES dan menerapkan model pengembangan waterfall, dengan harapan jika website e-Business nantinya diterapkan maka dapat memenuhi kualifikasi pada kerangka PIECES
\end{abstract}

Kata kunci : fotografi, e-Business, website, PIECES, waterfall

\section{PENDAHULUAN}

Dunia fotografi saat ini berkembang sangat pesat. Lebih dari sekadar teknologi, fotografi kini menjadi fenomena sosial. Di Indonesia saja, beragam komunitas fotografi banyak bermunculan. Komunitas-komunitas itu banyak yang lahir mengkhususkan berdasarkan minat, mencakup jenis kamera, teknik foto, objek foto, bahkan pendekatan tertentu. Bukti perkembangan dunia fotografi salah satunya dapat dilihat di situs www.fotografer.net. Situs ini menyediakan galeri secara gratis untuk para fotografer memasang foto-foto karyanya. Hingga bulan April 2005, hits FN mencapai 765.828 hit per hari dengan jumlah anggota terdaftar 42.500 orang, 161.008 foto, dan 2,3 juta kritik foto. Setiap harinya, FN dikunjungi hingga 4.700 unique visitor.

Selain itu, data penjualan kamera pun menunjukan bukti semakin booming-nya fotografi. Dikutip dari techno.okezone.com, tercatat data yang diperoleh Okezone pada konferensi pers, Senin, (9/2/2015) penjualan di pasar Asia termasuk Indonesia mengalami peningkatan sebesar 32 persen dari tahun 2005 hingga 2014. Perkembangan tersebut berdampak pada semakin tingginya kebutuhan masyarakat akan jasa fotografi.

Hal tersebut sejalan dengan perkembangan teknologi komputer, yang digunakan untuk membantu menghasilkan informasi secara efektif dan efisien. Pada sebuah perusahaan, pemanfaatan komputer untuk mengolah data dan menghasilkan informasi menjadi sangat penting. Seiring perkembangan komputer, penggunaan internet juga semakin meluas. Tersedianya fasilitas penunjang, kecepatan akses yang semakin tinggi dan biaya yang cukup terjangkau menjadikan internet umum digunakan. Bukan hanya untuk keperluan bisnis tapi sampai keperluan pribadi, hingga semua bidang kehidupan sudah tergantung pada internet dan internet pun menjadi kebutuhan sehari-hari.

Aspin Photography \& Video Pro merupakan sebuah studio foto yang lahir dan berkembang karena adanya fenomena fotografi belakangan ini. Aspin Photography \& Video Pro merupakan perusahaan yang bisnis utamanya bergerak di bidang jasa foto dan video yang berlokasi di Jl. Anggrek No. 27 Kelurahan Oepura Kota Kupang-NTT. Saat ini proses bisnis yang dijalankan pada Aspin Photography \& Video Pro masih dilakukan via telepon, aplikasi messenger atau secara langsung, dan pendataan setiap transaksi yang dilakukan pun dalam bentuk rekapan pada sebuah buku transaksi. Hal tersebut tentunya berdampak pada manajemen administrasi yang tidak rapi dan kesulitan dalam penyajian laporan. Selain itu, pihak Aspin Photography \& Video Pro belum mempunyasi sarana tetap untuk mempromosikan bisnis yang dijalankan.

Berdasarkan masalah yang telah dibahas dan dengan memanfaatkan penggunaan teknologi internet yang semakin luas maka penulis merumuskan judul "Pembangunan e-Business Berbasis Website Berdasarkan Kerangka PIECES (Studi Kasus: Aspin Photography \& Video Pro)".

\section{LANDASAN TEORI}

\section{PIECES Framework}

Teknik analisis ini dijelaskan dalam [1] untuk membuat sebuah sistem yang dibuat secara prototyping dengan melakukan analisa terlebih dahulu untuk mengetahui permasalahan dan kebutuhan untuk membuat sistem 
Sebuah sistem perlu ditemukan permasalahan yang ada agar sistem dapat berjalan dengan baik dan bisa mencapai tujuan yang diharapkan. Adapun beberapa aspek yang dapat dilihat dari analisis ini adalah sebagai berikut:

a. Performance (kinerja)

Diperlukan untuk menilai kinerja dari sistem yang terdiri dari:

1) Throughput: sistem dinilai dari banyaknya kerja (output) yang dilakukan pada beberapa periode waktu dalam memenuhi kebutuhan.

2) Respon time: waktu yang diperlukan oleh sistem informasi untuk melakukan proses kerja.

3) Audibilitas: keselarasan terhadap standar dapat diperiksa.

4) Kelaziman komunikasi: terkait user interface yang digunakan dalam sistem informasi dinilai dalam kemudahan untuk dipahami.

5) Kelengkapan: derajat dimana sistem informasi mempunyai fungsi yang penuh dalam mendukung pekerjaan.

6) Toleransi kesalahan: kerusakan yang terjadi pada saat program mengalami kesalahan.

b. Information and data (informasi dan data)

Diperlukan untuk menilai informasi yang dihasilkan dan data yang digunakan, terdiri dari:

1) Accuracy (akurat): informasi atas hasil evaluasi hendaklah memiliki tingkat ketepatan/ketelitian yang tinggi.

2) Relevansi informasi: informasi yang dihasilkan sesuai dengan kebutuhan.

3) Penyajian informasi: informasi disajikan dalam bentuk yang sesuai.

4) Aksesibilitas informasi: informasi dapat tersedia sewaktu-waktu ketika dibutuhkan.

c. Economic (ekonomi)

Diperlukan untuk menilai sistem informasi dari aspek ekonomi yang terdiri dari:

1) Reusabilitas: tingkat dimana sebuah program atau bagian dari program tersebut dapat digunakan kembali di dalam aplikasi yang lain.

2) Sumber daya: sumber daya yang digunakan dalam pengembangan sistem, meliputi sumber daya manusia serta sumber daya ekonomi.

d. Control and security (kontrol dan keamanan)

Digunakan untuk menilai sistem informasi dari aspek keamanan dan kontrol data yang terdiri dari:

1) Integritas: tingkat dimana akses ke perangkat lunak atau data oleh orang yang tidak berhak dapat dikontrol.

2) Keamanan: mekanisme yang mengontrol atau melindungi program dan data dalam sistem informasi.

e. Efficiency (efisiensi)

Digunakan untuk menilai sistem informasi dari aspek efisiensi yang terdiri dari:

1) Usabilitas: usaha yang dibutuhkan untuk mempelajari, mengoperasikan, menyiapkan input, dan menginterpretasikan output suatu program.
2) Maintanabilitas: usaha yang diperlukan untuk mencari dan membetulkan kesalahan pada sebuah program.

f. Service (pelayanan)

Digunakan untuk mengetahui bagaimana meningkatkan kepuasan pelanggan, pegawai dan manajemen. Aspek service (pelayanan) terdiri dari:

1) Akurasi: ketelitian komputasi dan kontrol.

2) Reliabilitas: tingkat dimana sebuah program dapat dipercaya dan diandalkan untuk melakukan fungsi yang diminta.

3) Kesederhanaan, yaitu tingkat dimana sebuah program dapat dipahami tanpa kesukaran.

\section{2. e-Business}

e-Business belakangan ini semakin sering didengar seiring perkembangan teknologi dan juga dunia bisnis. Terdapat berbagai macam definisi tentang e-Business, antara lain Kalakota dan Robinson yang mendefinisikan e-Business sebagai suatu gabungan yang kompleks dari proses bisnis, aplikasi perusahaan, dan struktur organisasi yang diperlukan untuk membuat model bisnis mempunyai kinerja yang tinggi [2]. Huff menjelaskan bahwa $e$ Business meliputi semua hal yang harus dilakukan menggunakan teknologi informasi dan komunikasi (ICT) untuk melakukan kegiatan bisnis antar organisasi maupun dari organisasi ke konsumen [3]. Defenisi lain menyatakan e-Business merupakan penggunaan internet dan teknologi digital lainnya untuk komunikasi, koordinasi, dan manajemen organisasi [4].

E-Business juga adalah praktek pelaksanaan dan pengelolaan proses bisnis utama seperti perancangan produk, pengelolaan pasokan bahan baku, manufaktur, penjualan, pemenuhan pesanan, dan penyediaan layanan melalui penggunaan teknologi komunikasi, komputer, dan data yang telah terkomputerisasi. E-Business menggunakan teknologi informasi berupa internet dan jaringan komputer lainnya untuk menjalankan proses bisnis utama yaitu pembelian dan penjualan. Awalan "e" dalam kata eBisnis berarti "elektronik", yang berarti kegiatan atau transaksi yang digunakan tanpa pertukaran atau kontak fisik, transaksi diadakan secara elektronik atau digital, hal ini menjadi mungkin dengan dukungan perkembangan komunikasi digital yang pesat [5]. Selain itu, definisi e-Business juga dikemukakan oleh Alter, yaitu praktek pelaksanaan dan pengelolaan proses bisnis utama seperti perancangan produk, pengelolaan pasokan bahan baku, manufaktur, penjualan, pemenuhan pesanan, dan penyediaan servis melalui penggunaan teknologi komunikasi, komputer, dan data yang telah terkomputerisasi [6].

Dalam mengimplementasikan konsep $e$ Business, terlihat jelas bahwa meraih keunggulan kompetitif (competitive advantage) jauh lebih mudah dibandingkan mempertahankannya. Secara teoritis hal tersebut dijelaskan karena adanya karakteristik sebagai berikut [7]: 
a. Pada level operasional, yang terjadi dalam $e$ Business adalah restrukturisasi dan redistribusi dari bit-bit digital (digital management), sehingga mudah sekali bagi perusahaan untuk meniru model bisnis dari perusahaan lain yang telah sukses.

b. Berbeda dengan bisnis konvensional di mana biasanya sebuah kantor beroperasi 8 jam sehari, di dalam e-Business (internet), perusahaan harus mampu melayani pelanggan selama 7 hari seminggu dan 24 jam sehari, karena jika tidak maka dengan mudah kompetitor akan mudah menyaingi perusahaan terkait.

c. Pelanggan dapat berinteraksi dengan perusahaan yang terkoneksi di internet, sehingga sangat mudah bagi mereka untuk pindah-pindah perusahaan dengan biaya yang sangat murah (rendahnya switching cost).

4. Fenomena jejaring (internet working) memaksa perusahaan untuk bekerja sama dengan berbagai mitra bisnis untuk dapat menawarkan produk atau jasa secara kompetitif, sehingga kontrol kualitas, harga, dan kecepatan sebuah produk atau jasa kerap sangat ditentukan oleh faktor-faktor luar yang tidak berada di dalam kontrol perusahaan.

\section{Website}

Website merupakan kumpulan halaman yang menampilkan informasi data teks, data gambar diam atau gerak, data animasi, suara, video, dan atau gabungan dari semuanya, baik yang bersifat statis maupun dinamis yang membentuk satu rangkaian bangunan yang saling terkait dimana masing-masing dihubungkan dengan jaringan-jaringan halaman (hyperlink) [8].

\section{Model Waterfall}

Model waterfall adalah model klasik yang bersifat sistematis, berurutan dalam membangun software. Nama model ini sebenarnya adalah "Linear Sequential Model". Model ini sering disebut juga dengan "classic life cycle" atau metode waterfall. Model ini termasuk kedalam model generic pada rekayasa perangkat lunak dan pertama kali diperkenalkan oleh Winston Royce sekitar tahun 1970 sehingga sering dianggap kuno, tetapi merupakan model yang paling banyak dipakai dalam Software Engineering [9]. Disebut dengan waterfall karena tahap demi tahap yang dilalui harus menunggu selesainya tahap sebelumnya dan berjalan berurutan. Adapun fase-fase dalam model waterfall:

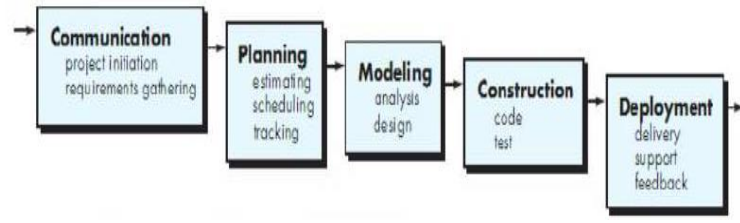

Gambar 1. Model Waterfall
a. Communication
(Project
Initiation
\& Requirements Gathering)
Sebelum memulai pekerjaan yang bersifat teknis, sangat diperlukan adanya komunikasi dengan customer demi memahami dan mencapai tujuan yang ingin dicapai. Hasil dari komunikasi tersebut adalah inisialisasi proyek, seperti menganalisis permasalahan yang dihadapi dan mengumpulkan data yang diperlukan, serta membantu mendefinisikan fitur dan fungsi software. Pengumpulan data tambahan bisa juga diambil dari jurnal, artikel, dan internet.

\section{b. Planning (Estimating, Scheduling, Tracking)}

Tahap berikutnya adalah tahapan perencanaan yang menjelaskan tentang estimasi tugas-tugas teknis yang akan dilakukan, risiko-risiko yang dapat terjadi, sumber daya yang diperlukan dalam membuat sistem, produk kerja yang ingin dihasilkan, penjadwalan kerja yang akan dilaksanakan, dan tracking proses pengerjaan sistem.

c. Modeling (Analysis \& Design)

Tahapan ini adalah tahap perancangan dan permodelan arsitektur sistem yang berfokus pada perancangan struktur data, arsitektur software, tampilan antarmuka, dan algoritma program. Tujuannya untuk lebih memahami gambaran besar dari apa yang akan dikerjakan. 


\section{d. Construction (Code \& Test)}

Tahapan construction ini merupakan proses penerjemahan bentuk desain menjadi kode atau bentuk/bahasa yang dapat dibaca oleh mesin. Setelah pengkodean selesai, dilakukan pengujian terhadap sistem dan juga kode yang sudah dibuat. Tujuannya untuk menemukan kesalahan yang mungkin terjadi untuk nantinya diperbaiki.

\section{e. Deployment (Delivery, Support, Feedback)}

Tahapan deployment merupakan tahapan implementasi software ke customer, pemeliharaan software secara berkala, perbaikan software, evaluasi software, dan pengembangan software berdasarkan

Tabel 1. Deksripsi masalah berdasarkan kerangka PIECES

\begin{tabular}{|c|c|c|}
\hline No. & Aspek & Permasalahan \\
\hline 1. & $\begin{array}{l}\text { Performance } \\
\text { (kinerja) }\end{array}$ & $\begin{array}{l}\text { Waktu yang dibutuhkan } \\
\text { untuk merespon } \\
\text { permintaan pelanggan } \\
\text { sebenarnya cukup baik, } \\
\text { tetapi pendataan yang } \\
\text { tidak rapi berdampak } \\
\text { pada layanan menjadi } \\
\text { lama. }\end{array}$ \\
\hline 2. & $\begin{array}{l}\text { Information } \\
\text { and data } \\
\text { (informasi dan } \\
\text { data) }\end{array}$ & \begin{tabular}{lrr} 
Belum & \multicolumn{2}{r}{ diterapkannya } \\
sebuah & basis data \\
sehingga & sulit mencari \\
informasi & dan juga \\
menghasilkan laporan. & Belum & tersedianya \\
Belum & saranya & penyajian \\
informasi & kepada \\
pelanggan & yang \\
lengkap. &
\end{tabular} \\
\hline 3. & $\begin{array}{l}\text { Economic } \\
\text { (ekonomi) }\end{array}$ & $\begin{array}{lr}\text { Pemborosan } & \text { waktu dan } \\
\text { SDM, karena } \\
\text { dibutuhkan } \\
\text { khusus untuk mengelola } \\
\text { administrasi. }\end{array}$ \\
\hline 4. & $\begin{array}{l}\text { Control and } \\
\text { security } \\
\text { (kontrol dan } \\
\text { keamanan) }\end{array}$ & $\begin{array}{l}\text { Data yang ada belum } \\
\text { memiliki keamanan dan } \\
\text { validasi sehingga rentan } \\
\text { terhadap kesalahan } \\
\text { pendataan maupun } \\
\text { kehilangan data yang } \\
\text { disengaja ataupun tak }\end{array}$ \\
\hline
\end{tabular}

\section{Tahap Planning}

Pada tahapan perencanaan ini dilakukan estimasi sumber daya manusia, waktu, anggaran, dan pembagian tugas dalam bentuk gantt chart.

\section{Tahap Modeling}

Tahap perancangan merupakan tahap pendekatan awal untuk menyelesaikan sebuah masalah.

a. Use case diagram umpan balik yang diberikan agar sistem dapat tetap berjalan dan berkembang sesuai dengan fungsinya.

\section{HASIL DAN PEMBAHASAN}

\section{Tahap Communication}

Pada tahapan ini dilakukan observasi dan wawancara dengan stakeholders e-Business guna memahami masalah dan tujuan yang diinginkan. Berdasarkan observasi terhadap proses bisnis yang dijalankan pada Aspin Photography \& Video Pro maka diidentifikasi beberapa permasalahan yang akan diuraikan berdasarkan kerangka PIECES berikut ini:

\begin{tabular}{|c|l|l|}
\hline & & $\begin{array}{l}\text { disengaja. } \\
\text { Kesulitan dalam } \\
\text { mengontrol transaksi } \\
\text { keuangan. }\end{array}$ \\
\hline 5. & $\begin{array}{l}\text { Efficiency } \\
\text { (efisiensi) }\end{array}$ & $\begin{array}{l}\text { Kinerja karyawan } \\
\text { menjadi kurang efisien } \\
\text { karena data tidak akurat. } \\
\text { Pengambilan keputuan } \\
\text { manajerial oleh } \\
\text { pemilik/pimpinan tidak } \\
\text { efisien bahkan sulit } \\
\text { dikarenakan model } \\
\text { administrasi yang tidak } \\
\text { menyajikan informasi } \\
\text { lengkap. }\end{array}$ \\
\hline 6. & $\begin{array}{l}\text { Pelayanan bersifat face } \\
\text { to face yang mana } \\
\text { pelanggan harus datang } \\
\text { untuk mengetahui detail } \\
\text { produk yang diinginkan } \\
\text { sehingga berdampak } \\
\text { pada waktu, biaya dan } \\
\text { tenaga. }\end{array}$ \\
\hline
\end{tabular}



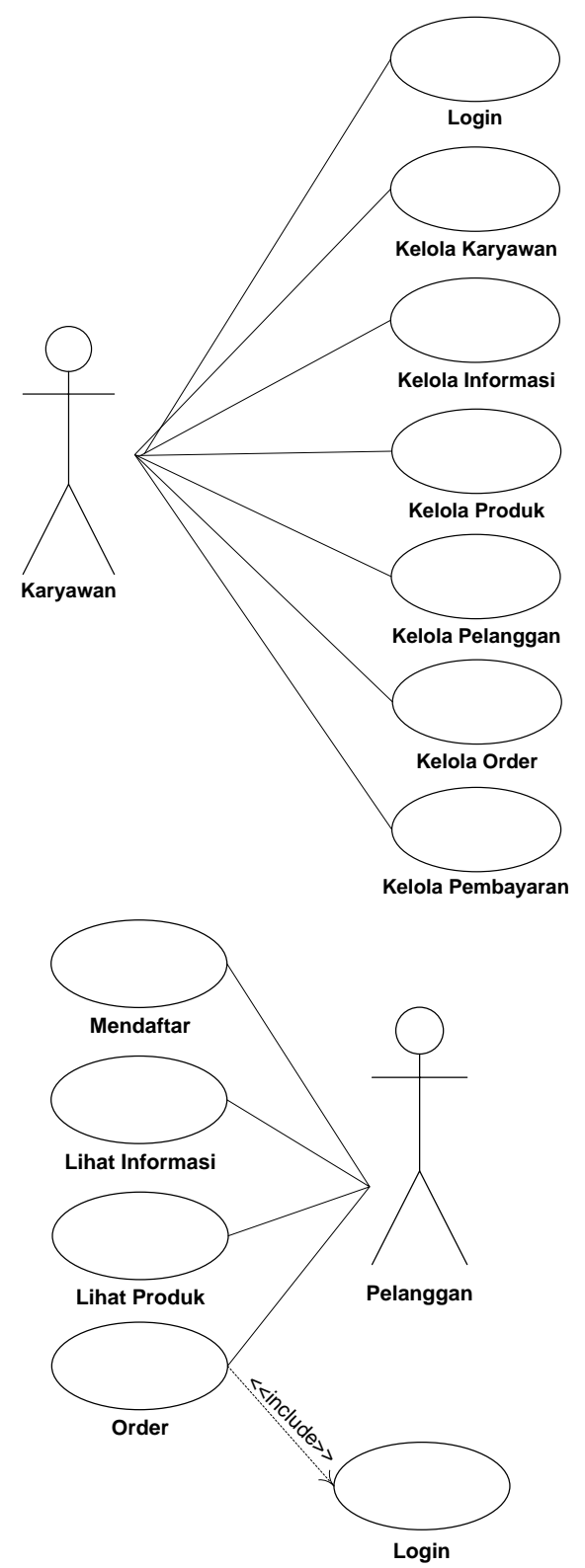

Gambar 2. Use case diagram e-Business

Pada use case diagram, actor pada $e$-Business adalah karyawan dan pelanggan. Karyawan dapat melakukan operasi mengelola data karyawan, informasi, produk, order, pembayaran hingga laporan, sedangkan pelanggan harus mendaftar atau melakukan registrasi agar bisa melakukan order karena pelanggan diwajibkan untuk login ke sistem agar dapat melakukan tarnsaksi. Untuk dapat mengakses halaman produk dan informasi bisa dilakukan oleh pengguna umum tanpa harus mendaftar/registrasi.

b. Class Diagram

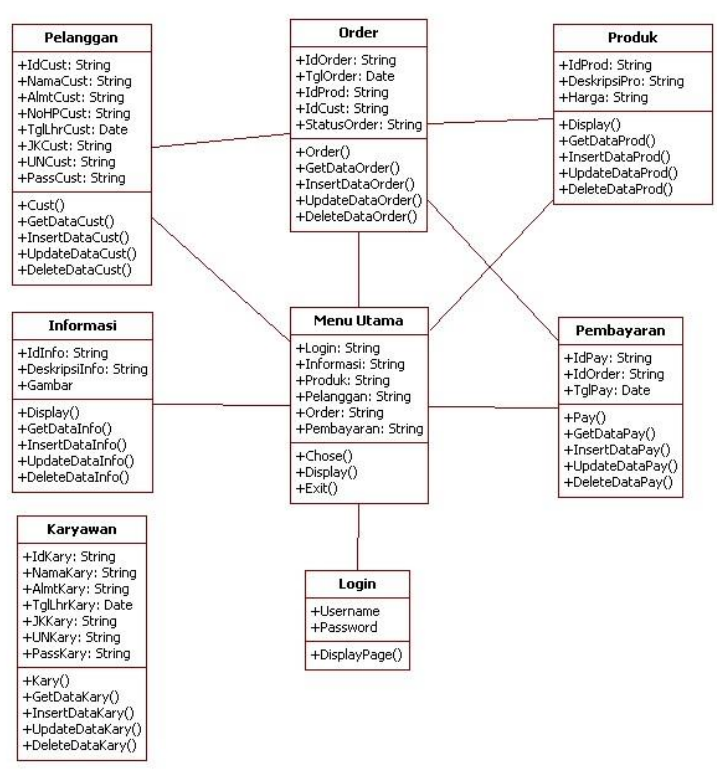

Gambar 3. Class diagram e-Business

c. Perancangan Antarmuka

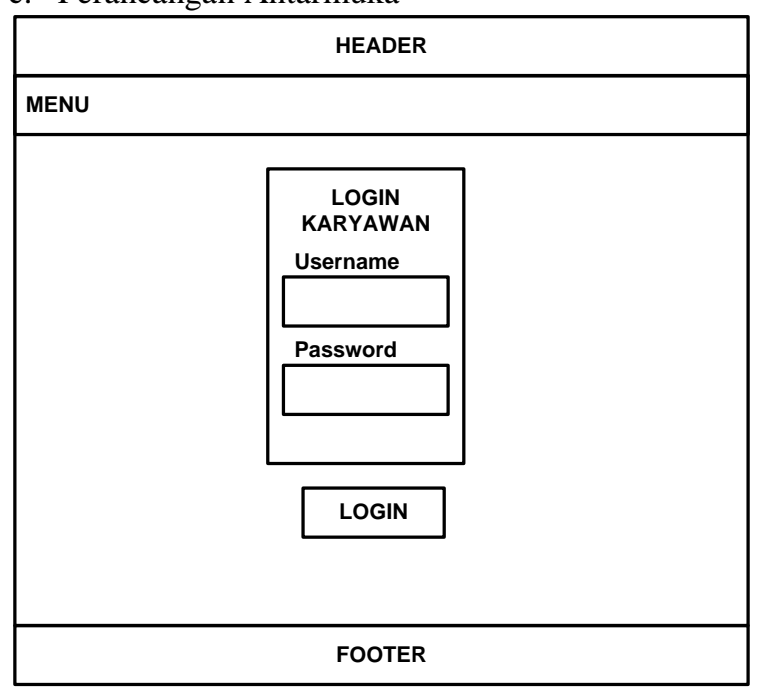

Gambar 4. Halaman login karyawan

\begin{tabular}{|l|}
\hline HEADER \\
\hline MENU \\
\hline Konten Informasi/ Tentang Kami \\
\hline xxxxxxxxxxxxxxxxxxxxxxxxxx \\
\hline Edit \\
\hline FOOTER \\
\hline
\end{tabular}

Gambar 5. Halaman kelola konten informasi 


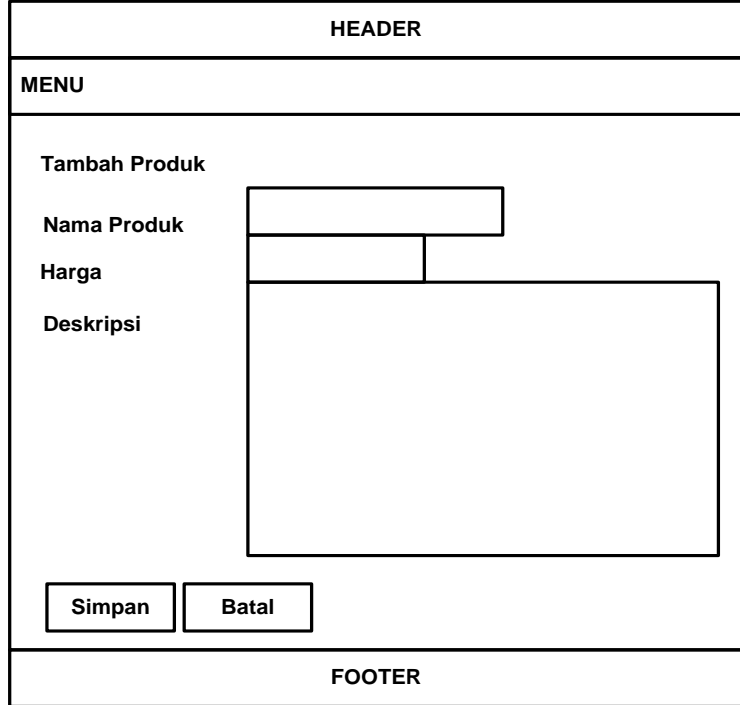

Gambar 6. Halaman kelola data produk

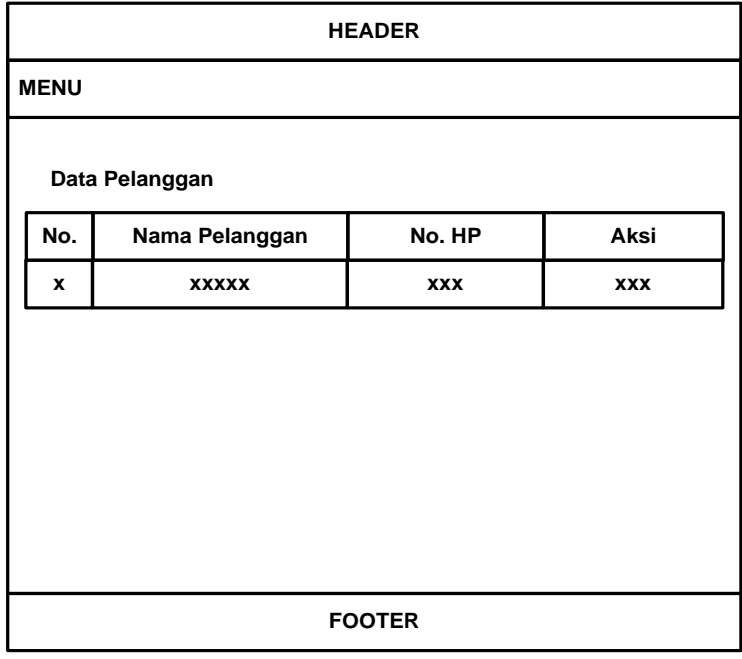

Gambar 7. Halaman kelola data pelanggan

\begin{tabular}{|c|c|c|c|}
\hline \multicolumn{4}{|c|}{ HEADER } \\
\hline \multicolumn{4}{|l|}{ MENU } \\
\hline \multicolumn{4}{|c|}{ Pesanan Masuk } \\
\hline \multicolumn{2}{|c|}{$\begin{array}{l}\text { No. } \\
\text { Order }\end{array}$} & Status & Aksi \\
\hline \multicolumn{2}{|c|}{$\mathbf{x}$} & $x x x$ & $x x x$ \\
\hline \multicolumn{4}{|c|}{ Detail Pesanan } \\
\hline $\begin{array}{l}\text { Nam } \\
\text { Alam } \\
\text { No. } \\
\end{array}$ & $\overline{\mathrm{Da}}$ & $\begin{array}{l}\text { No. Order } \\
\text { Tanggal Order } \\
\text { Jam Order } \\
\text { Status Order }\end{array}$ & $\begin{array}{l}\text { der } \\
: \text { xxxxxx } \\
: \text { xxxxxx } \\
: \text { xxxxxx } \\
: \\
\begin{array}{l}\text { Ubah } \\
\text { Status }\end{array}\end{array}$ \\
\hline No. & Nama Produk & Harga Satuan & Sub Total \\
\hline $\mathbf{x}$ & $\mathbf{x x x x x}$ & $\mathbf{x x x}$ & $\mathbf{x x x}$ \\
\hline \multicolumn{3}{|r|}{ Total } & $\mathbf{x x x}$ \\
\hline \multicolumn{2}{|c|}{ Kembali } & & \\
\hline & & & \\
\hline
\end{tabular}

Gambar 8. Halaman kelola data order dan pembayaran

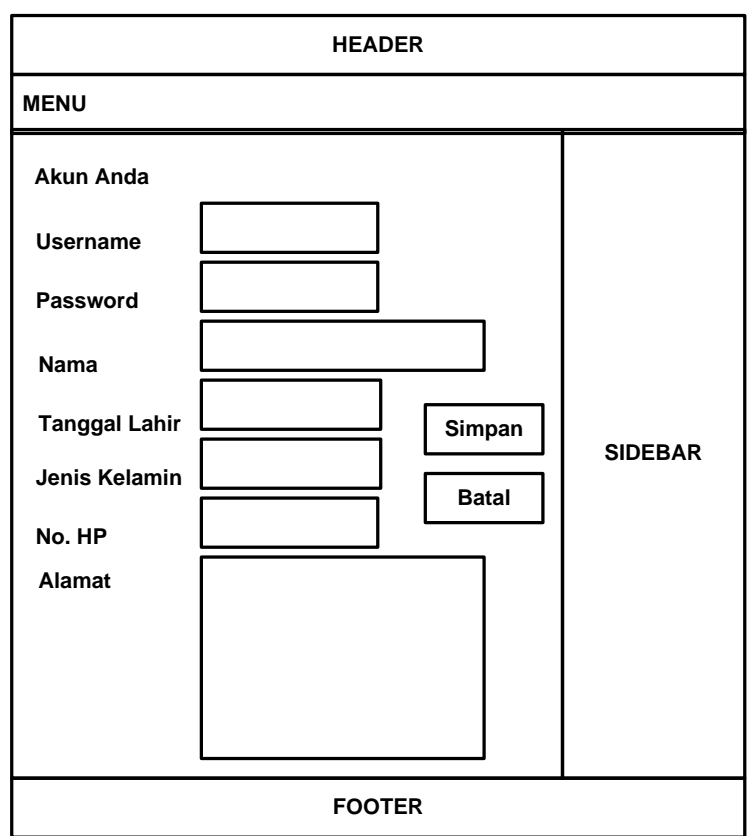

Gambar 9. Halaman daftar pelanggan

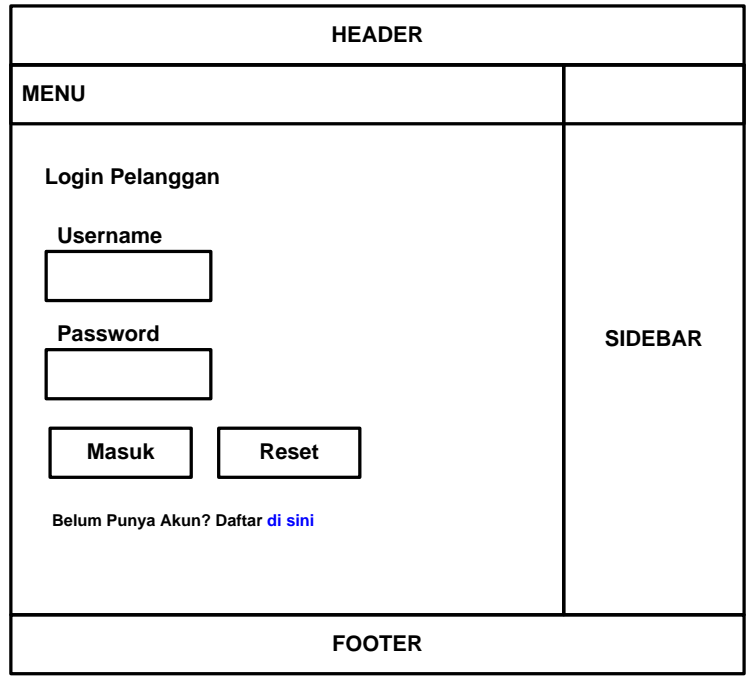

Gambar 10. Halaman login pelanggan

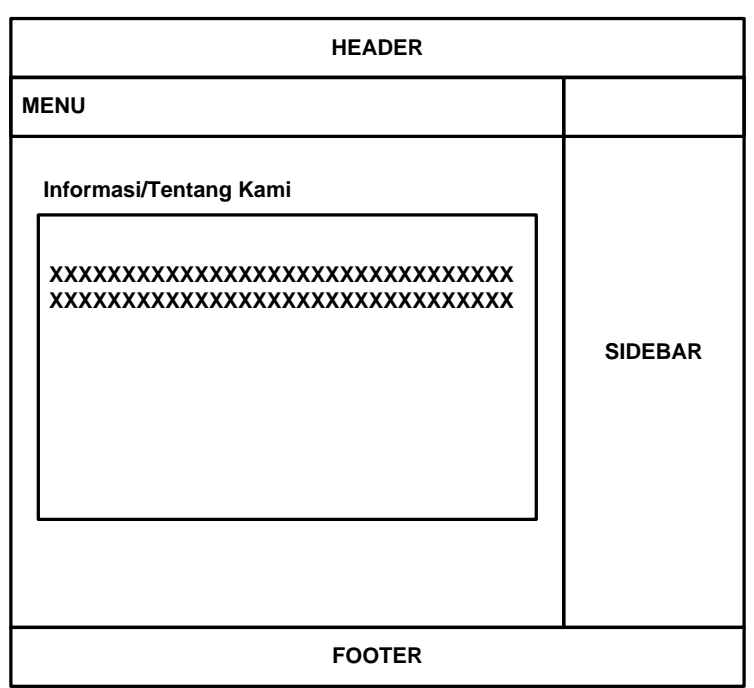

Gambar 11. Halaman lihat informasi 


\begin{tabular}{|c|c|c|c|}
\hline \multicolumn{4}{|c|}{ HEADER } \\
\hline \multicolumn{3}{|l|}{ MENU } & \\
\hline \multicolumn{3}{|c|}{ Daftar Produk Kami } & \multirow{7}{*}{ SIDEBAR } \\
\hline Nama Produk & Nama Produk & Nama Produk & \\
\hline Gambar & Gambar & Gambar & \\
\hline \begin{tabular}{|l} 
Pesan Sekarang \\
\end{tabular} & \begin{tabular}{|l|} 
Pesan Sekarang \\
\end{tabular} & \begin{tabular}{|l|} 
Pesan Sekarang \\
\end{tabular} & \\
\hline Nama Produk & Nama Produk & Nama Produk & \\
\hline Gambar & Gambar & Gambar & \\
\hline \begin{tabular}{|l} 
Pesan Sekarang \\
\end{tabular} & \begin{tabular}{|l|} 
Pesan Sekarang \\
\end{tabular} & Pesan Sekarang & \\
\hline & FOC & & \\
\hline
\end{tabular}

Gambar 12. Halaman lihat produk

\begin{tabular}{|c|c|c|c|}
\hline \multicolumn{4}{|c|}{ HEADER } \\
\hline \multicolumn{3}{|l|}{ MENU } & \\
\hline \multicolumn{3}{|c|}{ Daftar Pemesanan } & \multirow{6}{*}{ SIDEBAR } \\
\hline No. & Nama Produ & Harga & \\
\hline $\mathrm{x}$ & $\mathbf{x x x x x}$ & $\mathbf{x x x}$ & \\
\hline & & $\mathbf{x x x}$ & \\
\hline \multicolumn{2}{|c|}{ Konfirmasi Pemesanan } & Pemesanan & \\
\hline \multicolumn{3}{|c|}{ OTER } & \\
\hline
\end{tabular}

Gambar 13. Halaman order

\section{Tahap Construction}

a. Tampilan Website e-Business

Hasil pemodelan pada tahap sebelumnya kemudian dibangun untuk menjadi sebuah website dengan menggunakan PHP dan MySQL sebagai basis datanya. Adapun hasil dari website e-Business yang dibangun sebagai berikut:

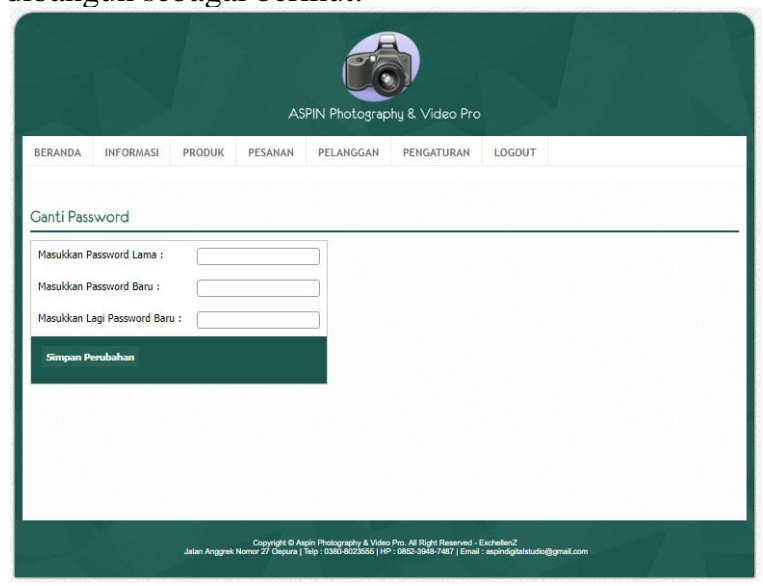

Gambar 14. Halaman login karyawan
Halaman ini digunakan oleh karyawan sebagai administrator website untuk masuk ke dalam website e-Business.

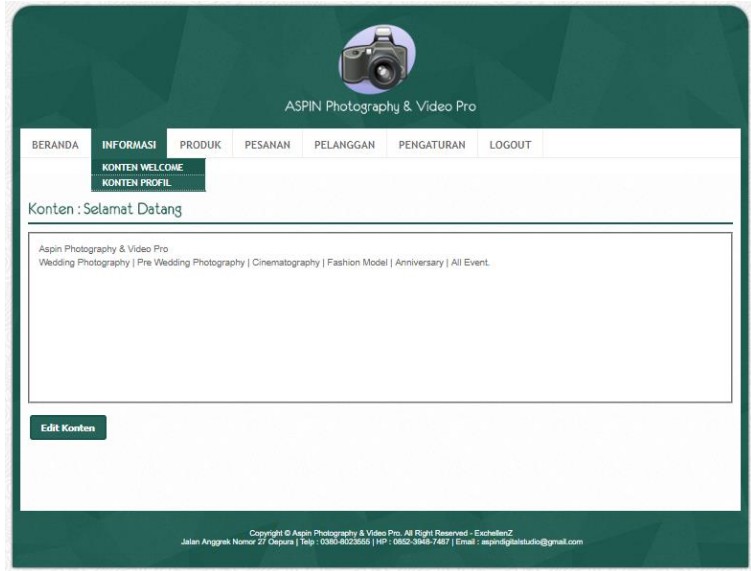

Gambar 15. Halaman kelola informasi

Konten informasi/tentang kami dikelola oleh karyawan sebagai administrator melalui halaman ini. Fungsi kelola yang dijalankan pada halaman ini adalah edit konten.

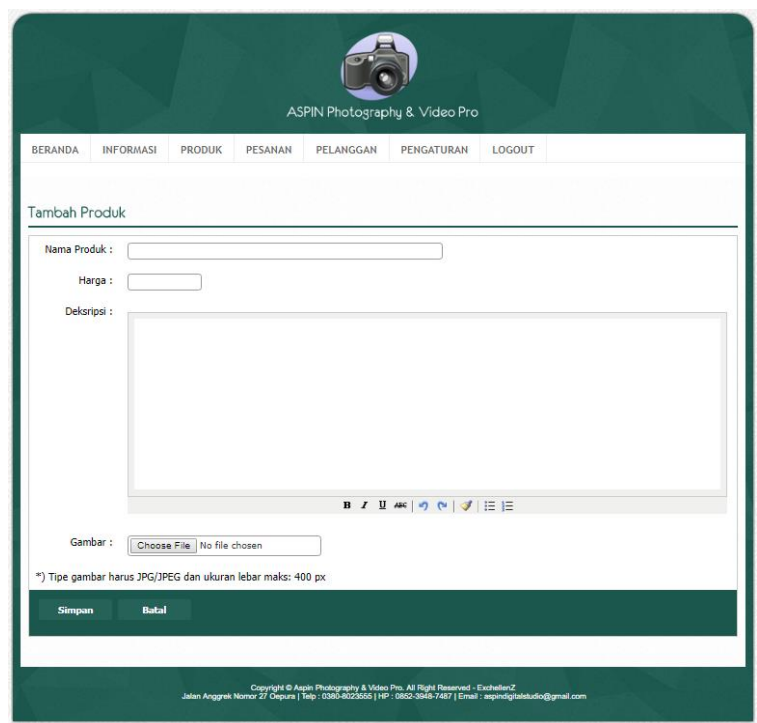

Gambar 16. Halaman kelola produk

Produk-produk yang ditawarkan oleh Aspin Photography \& Video Pro dikelola oleh karyawan sebagai administrator melalui halaman ini. Fungsi kelola yang dijalankan pada halaman ini antara lain simpan, hapus dan batal. 


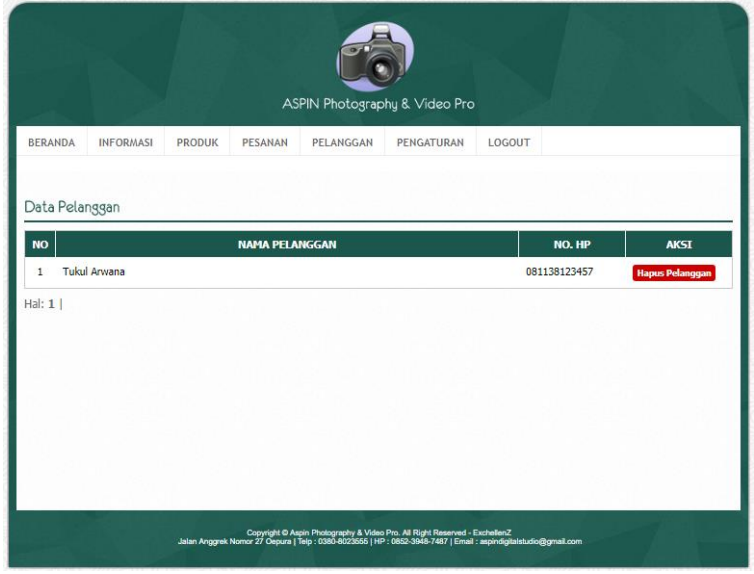

Gambar 17. Halaman kelola pelanggan

Pelanggan yang telah mendaftarkan diri pada website e-Business bisa dikelola oleh admin dengan mengakses halaman kelola data pelanggan.

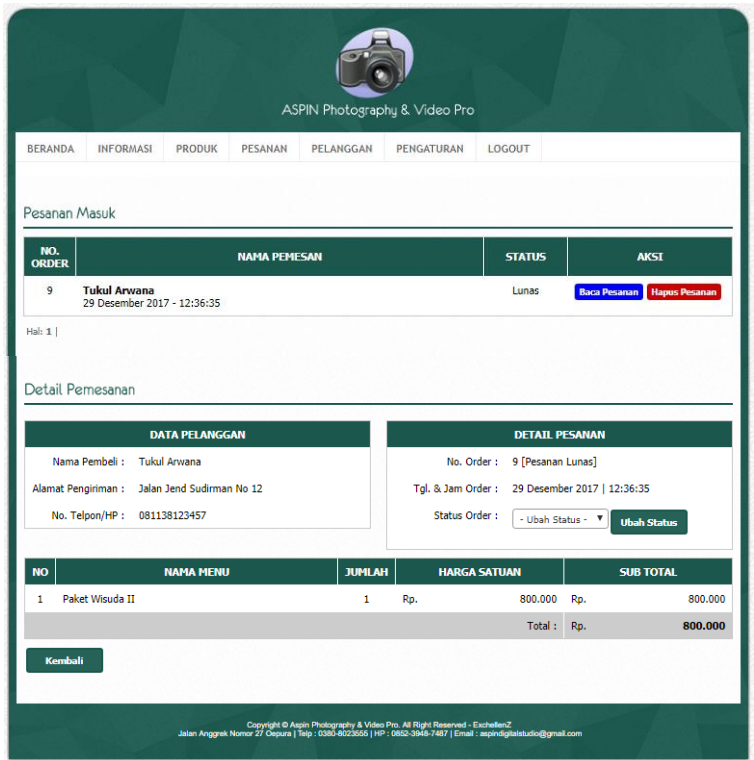

Gambar 18. Halaman kelola data order dan pembayaran

Pada halaman ini, data pemesanan produk yang telah dilakukan oleh pelanggan akan dikonfirmasi oleh administrator website. Pada halaman yang sama juga administrator bisa mengontrol status dari transaksi pembayaran yang dilakukan oleh pelanggan untuk selanjutnya dapat diproses.

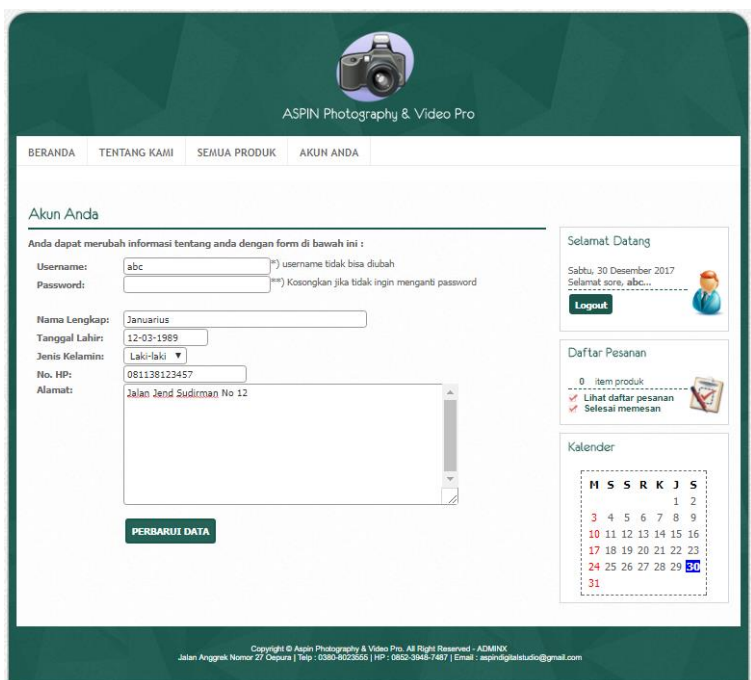

Gambar 19. Halaman pendaftaran pelanggan

Pelanggan yang hendak melakukan transaksi melalui website e-Business wajib mendaftarkan diri terlebih dahulu pada halaman ini. Selanjutnya, pelanggan bisa melakukan transaksi dengan melakukan login. Pelanggan yang telah terdaftar tidak perlu lagi untuk mengakses halaman ini jika ingin melakukan transaksi, tapi cukup dengan mengakses halaman login.

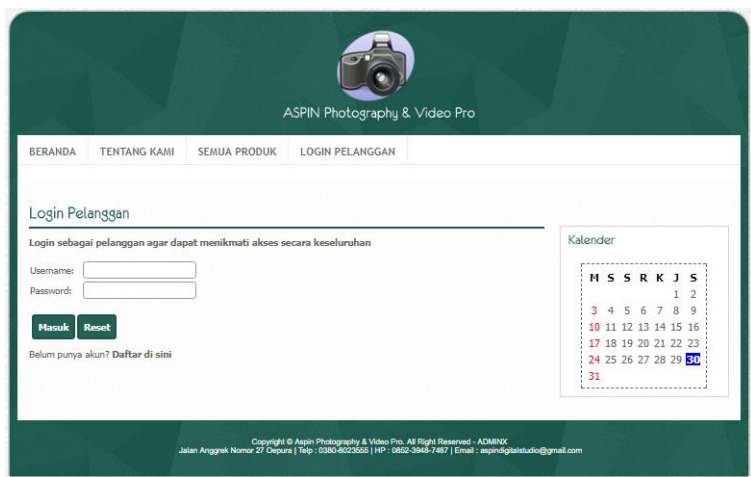

Gambar 20. Halaman login pelanggan

Halaman ini digunakan oleh pelanggan yang telah terdaftar untuk masuk ke dalam website $e$ Business kemudian melakukan transaksi. 


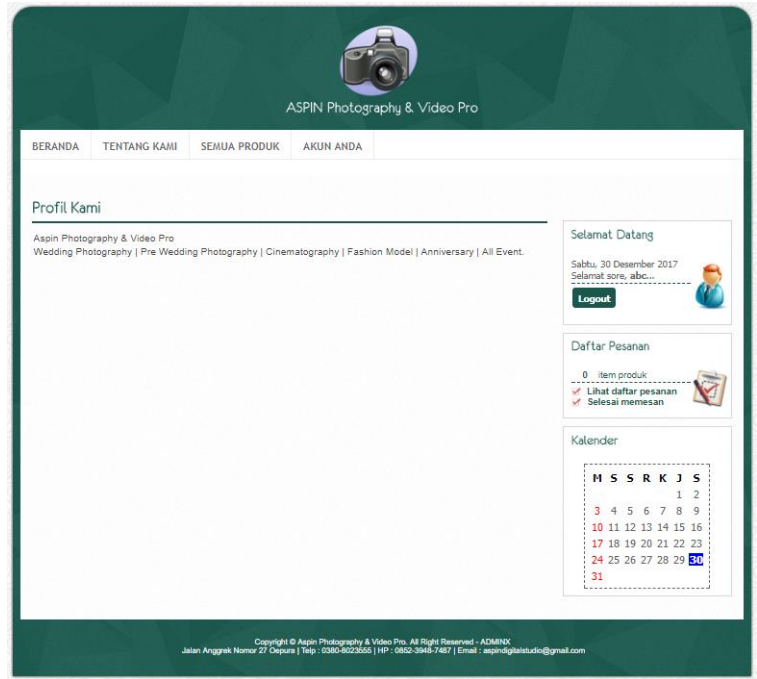

Gambar 23. Halaman order

Gambar 21. Halaman infomasi/tentang kami

Pada halaman ini para pelanggan baik yang telah terdaftar ataupun belum dapat melihat informasi yang berkaitan dengan Aspin Photography \& Video Pro

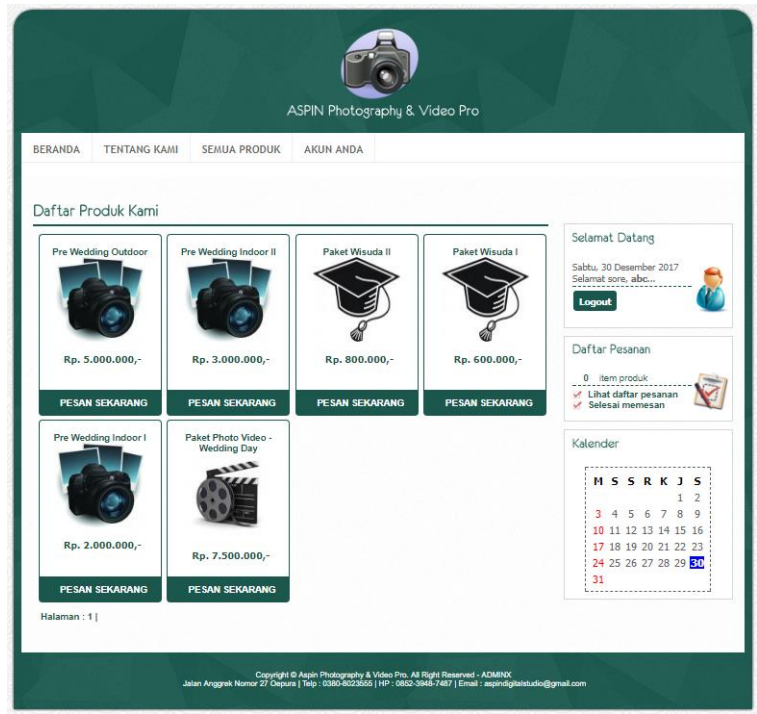

Gambar 22. Halaman produk

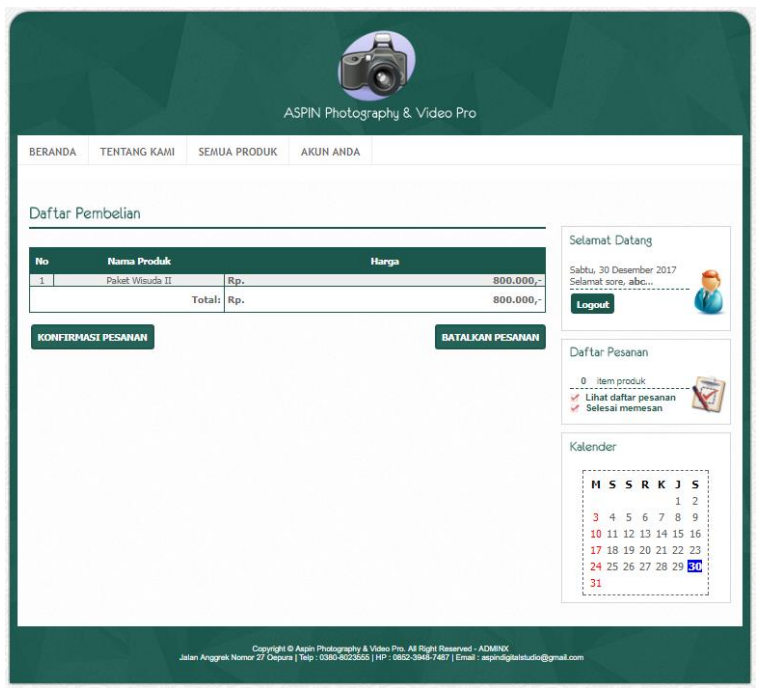


Halaman ini akan menampilkan status dan detail dari produk-produk yang dipesan oleh pelanggan melalui halaman produk pada Gambar 21 . Detail transaksi yang ditampilkan antara lain jenis produk dan biaya.

b. Pengujian Website
Proses pengujian yang dilakukan terhadap website e-Business ini adalah dengan menggunakan pengujian fungsional yang berguna untuk menguji fungsionalitas dari sebuah program. Parameter dan hasil pengujian yang dilakukan dapat dilihat pada tabel berikut:

Tabel 2. Hasil pengujian fungsional

\begin{tabular}{|c|c|c|c|c|}
\hline Detail pengujian & Proses & Luaran yang seharusnya & Luaran yang diperoleh & Status \\
\hline Login administrator & $\begin{array}{l}\text { Input username dan } \\
\text { password, klik login }\end{array}$ & $\begin{array}{l}\text { Masuk ke halaman beranda } \\
\text { administrator }\end{array}$ & $\begin{array}{l}\text { Masuk ke halaman } \\
\text { beranda administrator }\end{array}$ & Sukses \\
\hline Kelola informasi & Klik tombol edit & Informasi diperbarui & Informasi diperbarui & Sukses \\
\hline \multirow[t]{2}{*}{ Kelola produk } & Klik tombol simpan & Data produk tersimpan & Data produk tersimpan & Sukses \\
\hline & Klik tombol batal & Textbox kosong & Textbox kosong & Sukses \\
\hline Kelola pelanggan & Klik tombol hapus & $\begin{array}{l}\text { Data pelanggan yang } \\
\text { dipilih pada tabel terhapus }\end{array}$ & $\begin{array}{l}\text { Data pelanggan yang } \\
\text { dipilih pada tabel terhapus }\end{array}$ & Sukses \\
\hline \multirow[t]{2}{*}{ Kelola order } & $\begin{array}{l}\text { Klik tombol baca } \\
\text { pesanan }\end{array}$ & $\begin{array}{l}\text { Menampilkan data detail } \\
\text { pesanan yang dipilih pada } \\
\text { halaman detail pesanan }\end{array}$ & $\begin{array}{l}\text { Menampilkan data detail } \\
\text { pesanan yang dipilih pada } \\
\text { halaman detail pesanan }\end{array}$ & Sukses \\
\hline & $\begin{array}{l}\text { Klik tombol hapus } \\
\text { pesanan }\end{array}$ & $\begin{array}{l}\text { Data pesanan yang dipilih } \\
\text { pada tabel terhapus }\end{array}$ & $\begin{array}{l}\text { Data pesanan yang dipilih } \\
\text { pada tabel terhapus }\end{array}$ & Sukses \\
\hline Kelola pembayaran & Klik ubah status & $\begin{array}{l}\text { Status pembayaran dari } \\
\text { detail pesanan diperbarui }\end{array}$ & $\begin{array}{l}\text { Status pembayaran dari } \\
\text { detail pesanan diperbarui }\end{array}$ & Sukses \\
\hline Daftar pelanggan & Klik perbarui data & $\begin{array}{l}\text { Menampilkan pesan data } \\
\text { pelanggan yang diinput } \\
\text { pada textbox tersimpan }\end{array}$ & $\begin{array}{l}\text { Menampilkan pesan data } \\
\text { pelanggan yang diinput } \\
\text { pada textbox tersimpan }\end{array}$ & Sukses \\
\hline Login pelanggan & $\begin{array}{l}\text { Input username dan } \\
\text { password, klik login }\end{array}$ & Masuk ke halaman produk & Masuk ke halaman produk & Sukses \\
\hline Melihat informasi & Klik menu informasi & $\begin{array}{l}\text { Halaman informasi/ tentang } \\
\text { kami ditampilkan }\end{array}$ & $\begin{array}{l}\text { Halaman informasi/ } \\
\text { tentang kami ditampilkan }\end{array}$ & Sukses \\
\hline \multirow[t]{3}{*}{ Melakukan order } & $\begin{array}{l}\text { Klik tombol pesan } \\
\text { sekarang pada } \\
\text { produk yang dipilih }\end{array}$ & $\begin{array}{l}\text { Produk yang dipesan } \\
\text { ditampilkan pada halaman } \\
\text { order }\end{array}$ & $\begin{array}{l}\text { Produk yang dipesan } \\
\text { ditampilkan pada halaman } \\
\text { order }\end{array}$ & Sukses \\
\hline & $\begin{array}{l}\text { Klik tombol } \\
\text { konfirmasi pesanan }\end{array}$ & $\begin{array}{l}\text { Data detail produk yang } \\
\text { dipesan disimpan dan } \\
\text { tampil pada halaman } \\
\text { administrator }\end{array}$ & $\begin{array}{l}\text { Data detail produk yang } \\
\text { dipesan disimpan dan } \\
\text { tampil pada halaman } \\
\text { administrator }\end{array}$ & Sukses \\
\hline & $\begin{array}{l}\text { Klik tombol batalkan } \\
\text { pesanan }\end{array}$ & $\begin{array}{l}\text { Data pemesanan } \\
\text { pada halaman } \\
\text { terhapus }\end{array}$ & $\begin{array}{lr}\text { Data pemesanan } & \text { produk } \\
\text { pada halaman } & \text { order } \\
\text { terhapus } & \\
\end{array}$ & Sukses \\
\hline
\end{tabular}




\section{Tahap Deployment}

Pada tahapan ini dilakukan implementasi software ke customer agar dapat tetap berjalan dan bekerja sesuai dengan fungsinya.

Implementasi website e-Business ini harus memperhatikan spesifikasi kebutuhan perangkat keras (hardware) dan perangkat lunak (software). Dalam spesifikasi ini dijelaskan bahwa spesifikasi yang bagaimanakah yang paling tepat untuk menjalankan website ini agar dapat berjalan dengan normal yang tanpa masalah.

a. Spesifikasi kebutuhan administrator

Untuk mendukung kinerja administrator maka dibutuhkan komputer dengan sistem operasi minimal Windows 7, prosesor minimal dual core dan RAM minimal 2GB serta didukung dengan koneksi internet. Dibutuhkan juga perangkat lunak berupa browser untuk mengakses website.

b. Spesifikasi kebutuhan pelanggan

Untuk mengakses website e-Business dapat dilakukan melalui komputer ataupun smartphone karena website ini bersifat responsive. Dibutuhkan sebuah aplikasi browser untuk bisa mengakses website dan harus memperhatikan kulaitas koneksi internet.

\section{KESIMPULAN}

Berdasarkan hasil pengujian, semua fungsi dari website e-business dapat berjalan dengan baik. Dengan website ini, pihak Aspin Photography \& Video Pro dimudahkan dalam menjalankan proses promosi dan transaksi bisnisnya. Para pelanggan juga memperoleh manfaat karena bisa melakukan transaksi dimana saja dan kapan saja secara daring.
Hal penting yang perlu diperhatikan adalah terpenuhinya spesifikasi kebutuhan perangkat lunak, perangkat keras maupun koneksi internet baik dari pihak administrator maupun pelanggan agar website $e$-Business dapat berfungsi maksimal.

\section{REFERENSI}

[1] Whitten, J., Lonnie Bently. 2007. Systems Analysis and Design Methods Paperback. 7th edition. New York: McGraw-Hill.

[2] Kalakota, Ravi, Maria Robinson. 2001. eBusiness 2.0: A Roadmap for Success. USA: Addison Wesley.

[3] Huff, Sid L. 2002. Cases In Electronic Commerce. Boston: McGraw-Hill.

[4] Laudon, Kenneth C., Jane P. Laudon. 2001. Esssentials of Management Information Systems: Organization and Technology in Networked Enterprise. 4th edition. New Jersey: Prentice Hall.

[5] Sairamesh, J. 2004. Disconnected Processes, Mechanisms and Architecture for Mobile EBusiness. 9: 651-662. New York: Journal Association for Computing Machinery (ACM).

[6] Alter, S. 2002. Information Systems: Fundation of E-Business. New Jersey: Prentice Hall.

[7] Sutabri, T. 2012. Konsep Sistem Informasi. Yogyakarta: Andi Publisher.

[8] Fathurrahman. 2014. Membuat Website Mudah Dan Praktis Dengan Weebly. Jakarta: PT. Elex Media Komputindo.

[9] Pressman, R.S. 2014. Software Engineering: A Practioner's Approach. New York: McGrawHill 